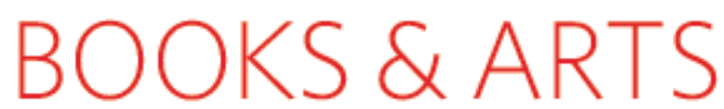

\title{
Enough is enough
}

Economic growth should be viewed as a means to an end, not an end in itself.

The Logic of Sufficiency

by Thomas Princen

MIT Press: 2005.401 pp. $\$ 29$

\section{Robert Costanza}

How much is enough? This is a question that is almost never asked in conventional discussions about the economy and society. The tacit assumptions are that there is never enough, that growth must continue indefinitely, and that, as Robert Heilbroner once put it: "the flow of goods and services consumed by everyone constitutes the ultimate aim and end of economic life. These assumptions are now so ingrained that to question them seems blasphemous, but a little research shows that they are fairly recent (post-Second World War) and are ultimately counterproductive in a finite (and full) world. Thomas Princen, associate professor of international natural resources and environmental policy at the University of Michigan, has added his voice to the growing chorus recognizing the ultimate futility of unlimited economic growth on a finite planet.

Princen's unique contribution to this discussion is his detailed and engaging history of the efficiency principle and its role in supporting the paradigm of unlimited economic growth. With its roots in factory management, efficiency has grown to encompass all aspects of modern life, Princen says. But efficiency requires specialization and a large scale, and for many workers this results in the removal of the elements of a job that make it fulfilling. Those elements include creativity, control and responsibility. Princen contrasts this with a proposed sufficiency principle, which places 'good' above 'ever better' and aims to provide a rationale for quality and sustainability.

He provides three detailed contemporary examples where the logic of sufficiency has been implemented and the systems have managed to survive and do well, while still embedded in the larger efficiency- and growthcrazed society. The first is the northern California Pacific Lumber Company's sustainable timber-harvesting policies; the second is the protected and restricted lobster fishery at Monhegan Island, Maine; the third is Toronto Island's policy of restricted car access. In each of these chapter-length examples, Princen details what can be achieved in terms of quality of life and sustainability by breaking with the idea that more is always better. The examples

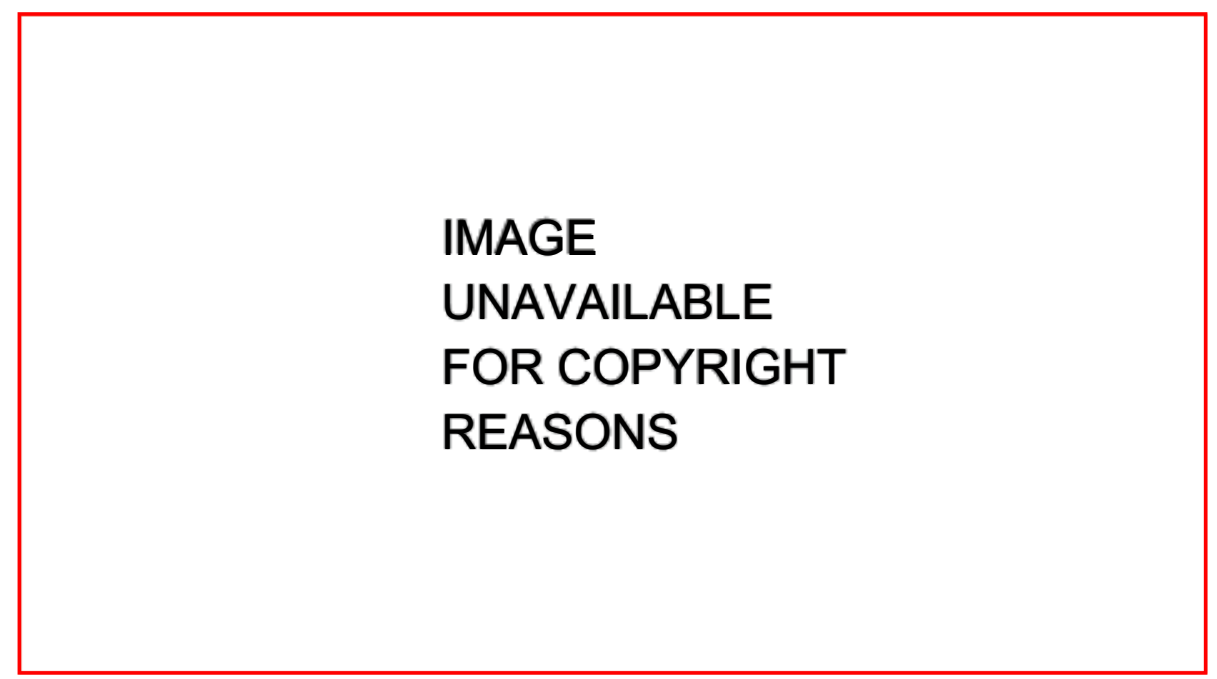

Protecting resources such as Borneo's rainforests can help give humanity a sustainable, desirable future.

also provide an existence proof for the sufficiency principle - solutions do exist.

Princen argues that if we adopt a "logic of sufficiency" rather than efficiency, the larger culture can also achieve these goals. There is much to like in this book, but it sets up a false dichotomy between efficiency and sufficiency, and ultimately misses the core issue - it is alternative goals, not just alternative rationalities, that lead to different results. The logic of efficiency can just as easily be used in the service of sustainability as in the service of growth.

The core problem is that we have forgotten that economic growth is a means to an end, not an end in itself. What, then, is the end? What is the shared goal of humanity? There is a growing consensus that this goal is (or should be) a sustainable and desirable present and future for all of humanity. It is not enough for the system to be merely sustainable, as an atrocious system might be sustainable indefinitely. Likewise, it is not enough for the system to be merely desirable, as desirability now may lead to misery later. It is also not enough for the system to be desirable in some of its aspects, but terrible in others. For example, economic development that causes environmental and social destruction that outweighs its gains is not real development at all. Finally, it is not enough for the system to be sustainable and desirable for a small élite, while leaving most people in sustainable misery.

If our goal is sustainable human well-being, we have to measure and include all the things that contribute to that goal. These not only include conventional economic goods and services, but also contributions from nature, from family, friends and other social relationships at many scales, and from health, education and fulfilling employment. One convenient way to summarize these contributions is to group them into four basic types of capital that are necessary to support the real, human-welfareproducing system: built capital, human capital, social capital and natural capital. Given the increasingly well known dependence of human well-being on ecosystem services and natural capital, this implies that maintaining our ecological life-support system and the biodiversity that allows it to function is a key sub-goal. Nature is not merely a luxury good.

Ultimately, to answer the question 'How much is enough?', one needs to specify 'for what purpose - towards what goal?'. If the purpose is 'more' then, obviously, there can never be enough. But if the goal is a sustainable and desirable future for all of humanity, then 'enough' has a clear meaning and imperative. Our challenge is to clearly articulate and agree on the vision of a sustainable and desirable future for humanity. Then we can clearly define what is sufficient to meet that goal, but we can also be efficient in achieving it. Robert Costanza is at the Gund Institute of Ecological Economics, University of Vermont, Burlington, Vermont 05405-1708, USA. 